\title{
Comparing key characteristics of young adult crack users in and out-of-treatment in Rio de Janeiro, Brazil
}

\author{
Marcelo Cruz ${ }^{1}$, Neilane Bertoni ${ }^{2}$, Francisco I Bastos ${ }^{2}$, Chantal Burnett ${ }^{3}$, Jenna Gooch ${ }^{3}$ and Benedikt Fischer $3,4,5^{*}$
}

\begin{abstract}
Background: Crack use is prevalent among street drug users in Brazilian cities, yet despite recent help system reforms and investments, treatment utilization is low. Other studies have identified a variety of - often inconsistent factors associated with treatment status among crack or other drug users. This study compared socio-economic, drug use, health and service use characteristics between samples of young adult crack users in- and out-of-treatment in Rio de Janeiro, Brazil.
\end{abstract}

Findings: Street-involved crack users ( $n=81$ ) were recruited by community-based methods, and privately assessed by way of an anonymous interviewer-administered questionnaire as well as biological methods, following informed consent. In-treatment users $(n=30)$ were recruited from a public service in-patient treatment facility and assessed based on the same protocol. Key indicators of interest were statistically cross-compared. Not-in-treatment users were less likely to: be white, educated, stably housed, to be involved in drug dealing, to report lifetime marijuana and current alcohol use, to report low mental health status and general health or addiction/mental health care; they were more likely to: be involved in begging and utilize social services, compared to the in-treatment sample (statistical significance for differences set at $p<.05)$.

Conclusions: In-treatment and not-in-treatment crack users differed on several key characteristics. Overall, in-treatment users appeared to be more socio-economically integrated and connected to the health system, yet not acutely needier in terms of health or drug problems. Given overall low treatment utilization but high need, efforts are required to facilitate improved treatment access and use for marginalized crack users in Brazil.

Keywords: Brazil, Crack use, Health characteristics, Marginalization, Treatment access, Service utilization

\section{Introduction}

Crack use is prevalent and entails extensive health and social problems in Brazil. There may be up to 1 million crack users in Brazil [1,2]; most are young, poor, socioeconomically marginalized and crime-involved [3]. Most feature extensive poly-substance use (including alcohol, marijuana, stimulants/inhalants), yet do not engage in injection drug use (IDU); hence, blood borne virus (BBV), e.g., HIV or Hepatitis C Virus (HCV), rates are

\footnotetext{
* Correspondence: bfischer@sfu.ca

${ }^{3}$ Centre for Applied Research in Mental Health and Addiction (CARMHA), Faculty of Health Sciences, Simon Fraser University, 2400-515 West Hastings St., Vancouver V6B 5 K3, Canada

${ }^{4}$ Social \& Epidemiological Research, Centre for Addiction and Mental Health, 33 Russell St., Toronto M6J 1H4, Canada

Full list of author information is available at the end of the article
}

comparably low among Brazilian crack users [4,5]. Violence, e.g., related to drug markets, contributes to high levels of injury and mortality among users, and social problems in many urban communities in Brazil $[6,7]$.

While care (including treatment) services for substance use problems have been expanded in Brazil in recent years, their utilization - specifically by crack users - appears rather limited [8,9]. However, it is unclear whether these patterns are mainly determined by limitations in service availability, or access barriers between services and the (marginalized) user populations [9].

Studies examining differences between crack/cocaine as well as opioid/heroin user populations in and out-oftreatment have predominantly found the latter subgroups to be more commonly characterized by social marginalization (e.g., unstable housing, unemployment) 
and limited social supports; lengthier, more complex and/ or problematic drug use histories or patterns; more intensive (physical and/or mental) health problems; and higher crime or criminal justice involvement; however, findings are heterogeneous and inconsistent [10-13]. While comparative Brazilian studies are scarce, Ferri et al. found higher levels of homelessness, sex trade, crime and problematic substance use among out-of-treatment compared to in-treatment cocaine users in Sao Paulo [14]. Malta et al. [8] found socio-demographic factors (race, education, employment) to be associated with treatment-seeking among impoverished drug users in Rio de Janeiro (RdJ).

The purpose of this study was to compare key socioeconomic, drug use and health characteristics of two samples of young adult in- and out-of-treatment crack users in RdJ, Brazil; given the acute extent of crack use in Brazil yet low treatment utilization, this comparative analysis aids to identify potential factors differentiating treatment status, and to inform interventions towards improving treatment access and/or utilization.

\section{Findings \\ Methods}

The study conducted a comparative, cross-sectional assessment of two community-recruited convenience samples of young out-of-treatment and in-treatment crack users. Eligibility criteria for both samples were: 1) Crack use on $3+$ days/week in last 3 months (for in-treatment participants, this criterion applied to pre-treatment entry); 2) 18-24 years of age; 3 ) ability to consent to study protocol, facilitating basic comparability of retrospective data on these grounds. Street-involved users were recruited by way of community-based outreach methods in a poor neighborhood (Jazarezinho) of RdJ known for street drug use. Local community contacts distributed key study information among users, and prospective participants underwent a brief in-person eligibility assessment. The treatment sample was recruited from among in-patients in a public drug treatment clinic (capacity: 90 beds; average program duration 30-45 days, with most admissions by self- or family-referral) in RdJ. Similarly, potentially eligible patient participants recruited in the clinic were informed about the study by clinic staff in the clinic setting, then contacted study staff if they expressed interest and were subsequently screened for eligibility. The locale from which street users were recruited and the clinic are situated within different parts of RdJ. The clinic is the only general and public referral clinic in RdJ for in-patient drug abuse treatment mainly catering to poor and marginalized users. While the clinic's crack user patients are referred from different neighborhoods across the city, including the one where street users were recruited, the general profile of the clinic's patient population allows to reasonably assume the inclusion of overall similar and comparable study populations.

Upon eligibility confirmation and provision of informed consent, participants were assessed via an intervieweradministered, anonymous questionnaire comprising social, drug use, and health characteristics; furthermore, blood samples for anonymous BBV testing were collected. Assessments took about 45-60 minutes, and were conducted by field research assistants trained and experienced in field research with marginalized populations. Participants received a public transportation pass for their time and efforts. The study protocol was approved by the Ethical Review Committee, Institute of Psychiatry, Federal University of Rio de Janeiro, as well as the Brazilian National Ethics Committee (CONEP 519/2010; see also [9] for additional study details).

A total of $n=81$ street-involved, and $n=30$ intreatment users were assessed between November 2010 and July 2011. Data were entered into an electronic database; descriptive statistics on relevant outcome indicators were computed with SPSS. Specifically, we computed proportions for categorical variables, and means for continuous variables, including 95\% Confidence Intervals (CI), and statistically compared these indicators between the two groups by way of chi-square and $\mathrm{t}$-tests, respectively, with significance levels set at $\mathrm{p}<.05$.

\section{Results}

The mean age in both samples was 21 years (range 1824; SD: 2; data not shown). Respective majorities in both samples were male; single or separated; unemployed and had been arrested; a minority in both groups engaged in sex work. The street sample: included fewer white people; had lower education; was more likely to be unstably housed and to be involved in begging - but less likely to be involved in drug dealing - than the treatment sample (Table 1).

Both samples, on average, had a history of about 4 years of crack use as well as reported between 10 and 12 crack use episodes per day (data not shown). None except one participant had an IDU history. A larger proportion of non-treatment participants shared crack pipe implements. Approximately half or more participants in both samples reported lifetime and current use of alcohol, tobacco, marijuana and cocaine. Larger proportions in the treatment sample reported current (i.e., past 30 days) alcohol use (Table 2).

About half the participants in both samples reported physical health to be 'good' or better, and that they had some physical health problems. While about a third in each group reported mental health problems, fewer about half - of in-treatment participants rated their mental health to be 'good' or better. A majority in both samples reported unsafe sex, while only a minority had 
Table 1 Socio-demographic and -economic characteristics of samples

\begin{tabular}{|c|c|c|c|c|c|c|}
\hline & \multicolumn{3}{|c|}{ Street sample $(n=81)$} & \multicolumn{3}{|c|}{ Treatment sample $(n=30)$} \\
\hline & $\mathrm{n}$ & $\%$ & $95 \% \mathrm{Cl}$ & $\mathrm{n}$ & $\%$ & $95 \% \mathrm{Cl}$ \\
\hline \multicolumn{7}{|l|}{ Sex } \\
\hline Male & 54 & 67 & $57-77$ & 23 & 79 & $64-94$ \\
\hline Female & 26 & 33 & $23-43$ & 6 & 21 & $6-36$ \\
\hline \multicolumn{7}{|l|}{ Colour/Race $\left[{ }^{*}\right]$} \\
\hline White & 8 & 10 & $4-17$ & 8 & 27 & $11-43$ \\
\hline Non-white & 73 & 90 & $84-97$ & 22 & 73 & $57-89$ \\
\hline \multicolumn{7}{|l|}{ Marital status } \\
\hline Single or separated & 70 & 86 & 79-94 & 24 & 80 & $66-94$ \\
\hline Married or co-habitating & 11 & 14 & $6-22$ & 6 & 20 & $6-34$ \\
\hline \multicolumn{7}{|l|}{ Education [*] } \\
\hline No formal education or some elementary school & 69 & 86 & $79-94$ & 14 & 47 & $29-65$ \\
\hline Completed elementary school or higher & 11 & 14 & $6-22$ & 16 & 53 & $35-71$ \\
\hline \multicolumn{7}{|l|}{ Housing status $[30][*]$} \\
\hline Stable & 20 & 25 & $16-35$ & 27 & 90 & $80-101$ \\
\hline Unstable (including homelessness) & 60 & 75 & $66-85$ & 3 & 10 & $0-21$ \\
\hline \multicolumn{7}{|l|}{ Employment status [30] } \\
\hline Employed or working & 33 & 41 & $30-52$ & 15 & 50 & $32-68$ \\
\hline Not employed & 48 & 59 & $48-70$ & 15 & 50 & $32-68$ \\
\hline \multicolumn{7}{|l|}{ Arrested (in past year) } \\
\hline Yes & 23 & 28 & $18-38$ & 12 & 40 & $23-58$ \\
\hline No & 58 & 72 & $62-82$ & 18 & 60 & $43-76$ \\
\hline \multicolumn{7}{|l|}{ Drug dealing for income $[30][*]$} \\
\hline Yes & 7 & 9 & $3-15$ & 8 & 27 & $11-43$ \\
\hline No & 74 & 91 & $75-91$ & 22 & 73 & $57-89$ \\
\hline \multicolumn{7}{|l|}{ Sex work for income [30] } \\
\hline Yes & 14 & 17 & $9-25$ & 3 & 10 & $0-21$ \\
\hline No & 67 & 83 & $75-91$ & 27 & 90 & 79-101 \\
\hline \multicolumn{7}{|l|}{ Begging for income [30] [*] } \\
\hline Yes & 20 & 25 & $16-34$ & 1 & 3 & $0-9$ \\
\hline No & 61 & 75 & $66-84$ & 29 & 97 & $91-103$ \\
\hline
\end{tabular}

ever been HIV tested. Small proportions in both groups were HBV (antigen) positive; a small proportion in the street group was HIV-positive. Minorities in each group reported general health, specialized addiction/mental health, and social service utilization; social service utilization was higher among non-treatment users; general and specialized health service utilization was higher among in-treatment users (Table 3).

\section{Discussion}

We found notable differences in key characteristics between the non-treatment and treatment samples of crack users, several of which mirror findings from other studies. For example, lower rates of visible minorities (e.g., non-whites) and higher education status have been found among in-treatment samples elsewhere, suggesting that socio-economic status may play a role in treatment seeking or access; this could relate to the access of relevant information, the management of bureaucratic systems or simply monetary resources $[8,12,13]$. Housing status is recognized as a primary determinant of health, and specifically for risk and harm outcomes among drug users $[15,16]$. Thus, it may act as a form of 'social capital' facilitating the dynamics of treatment access 
Table 2 Crack and other drug use characteristics of samples

\begin{tabular}{|c|c|c|c|c|c|c|}
\hline & \multicolumn{3}{|c|}{ Street sample $(n=81)$} & \multicolumn{3}{|c|}{ Treatment sample $(n=30)$} \\
\hline & $\mathbf{N}$ & $\%$ & $95 \% \mathrm{Cl}$ & $n$ & $\%$ & $95 \% \mathrm{Cl}$ \\
\hline \multicolumn{7}{|l|}{ Shared crack implements [30] [*] } \\
\hline Yes & 49 & 60 & $49-71$ & 8 & 27 & $11-43$ \\
\hline No & 32 & 40 & $29-51$ & 22 & 73 & $57-89$ \\
\hline \multicolumn{7}{|l|}{ Shared $>10$ time (among sharers) } \\
\hline Yes & 33 & 67 & $54-80$ & 3 & 38 & $4-72$ \\
\hline No & 16 & 33 & $20-46$ & 5 & 62 & $28-96$ \\
\hline \multicolumn{7}{|l|}{ Drug injection history (ever) } \\
\hline Yes & 0 & $\mathrm{n} / \mathrm{a}$ & $\mathrm{n} / \mathrm{a}$ & 1 & 3 & $\mathrm{n} / \mathrm{a}$ \\
\hline No & 81 & 100 & $\mathrm{n} / \mathrm{a}$ & 29 & 97 & $91-100$ \\
\hline \multicolumn{7}{|l|}{ Use of other drugs [30] } \\
\hline Alcohol [*] & 21 & 34 & $22-46$ & 13 & 65 & $43-85$ \\
\hline Tobacco & 70 & 92 & $86-98$ & 25 & 96 & $89-100$ \\
\hline Cocaine & 14 & 26 & $14-38$ & 9 & 45 & $23-67$ \\
\hline Marijuana & 42 & 64 & $52-76$ & 19 & 66 & $49-83$ \\
\hline Benzodiazepines & 0 & $\mathrm{n} / \mathrm{a}$ & $\mathrm{n} / \mathrm{a}$ & 1 & 33 & $\mathrm{n} / \mathrm{a}$ \\
\hline Inhalants (e.g., glue, solvents) & 2 & 5 & $0-12$ & 2 & 20 & $0-43$ \\
\hline
\end{tabular}

[30]: In past 30 days.

$\left[{ }^{*}\right]$ Chi-square significant at $\mathrm{p}<0.05$ level.

$[10,12,14]$. While less intensely crime-involved individuals are generally more likely to access treatment, our treatment sample indicated more prolific involvement in drug dealing (but less begging) [14]. There is no readily evident explanation for this difference, also since the treatment program under study did not include compulsory treatment referrals.

While the two groups showed similar crack and IDU patterns, the non-treatment group featured a higher prevalence of crack implement sharing - a risk behavior that possibly facilitates BBV (e.g., HCV) transmission [17]. This mirrors other studies' findings that key risk behaviors (e.g., needle sharing) are more commonly found among socio-economically marginalized (e.g., homeless) drug users $[16,18]$. The groups featured similar profiles of other current (non-crack) drug use, with the exception of alcohol use which was more prevalent among the in-treatment group. Since the intensity of drug use patterns or problems can influence treatmentseeking [19], alcohol-related problems may have been a factor in treatment-seeking in the in-treatment group; however, we do not have evidence for other, similar drug use-related differentiating factors which hence likely need to be identified in other individual or ecological domains.

Users' physical and mental health status are associated with treatment access and status [20,21]. Our study's intreatment group indicated lower mental health status self-ratings which - while no differences were found for mental health problems - may directly relate to the severity of crack or other drug use related problems (e.g., withdrawal) experienced, or otherwise motivated treatment seeking. We found important differences regarding health and social service utilization patterns. While any service utilization was limited to respective sample minorities, higher social service utilization among non-treatment participants may suggest higher need for and reliance on 'survival' services (e.g., food-banks, shelter), consistent with their higher socio-economic marginalization. Conversely, the in-treatment group appeared to be better connected with health services, which may be a factor facilitating treatment access.

While extensive treatment needs for crack use appear to exist, treatment service access and utilization have been found to be distinctly low in Brazil (e.g., $[8,9])$. In-treatment users in this study were less socioeconomically marginalized (e.g., regarding education, housing) and more connected to the service system. These factors have been recognized as important in facilitating health service utilization among drug users $[22,23]$. Correspondingly, the more marginalized crack users were less likely to access or utilize treatment (and other health services). This is disconcerting also since marginalized drug users typically feature more acute or severe health risks or care needs [16]. Multi-site data are needed to compare the situation, and related factors, to elsewhere in Brazil. In the context of extensive prevalence of crack use and harms in Brazil, our study's 
Table 3 Key health and service utilization indicators of samples

\begin{tabular}{|c|c|c|c|c|c|c|}
\hline & \multicolumn{3}{|c|}{ Street sample $(n=81)$} & \multicolumn{3}{|c|}{ Treatment sample $(n=30)$} \\
\hline & $\mathrm{n}$ & $\%$ & $95 \% \mathrm{Cl}$ & $\mathbf{n}$ & $\%$ & $95 \% \mathrm{Cl}$ \\
\hline \multicolumn{7}{|l|}{ Self-rated physical health status [30] } \\
\hline Excellent, very good, or good & 43 & 53 & $42-64$ & 13 & 43 & $25-61$ \\
\hline Fair or poor & 38 & 47 & $36-58$ & 17 & 57 & $39-75$ \\
\hline \multicolumn{7}{|l|}{ Physical health problems [30] } \\
\hline Yes & 32 & 41 & $30-52$ & 12 & 41 & $23-59$ \\
\hline No & 47 & 59 & $48-70$ & 17 & 59 & $41-77$ \\
\hline \multicolumn{7}{|c|}{ Self-rated mental health status $[30]\left[{ }^{*}\right]$} \\
\hline Excellent, very good, or good & 45 & 56 & $45-67$ & 9 & 31 & $14-48$ \\
\hline Fair or poor & 35 & 44 & $33-54$ & 20 & 69 & $52-86$ \\
\hline \multicolumn{7}{|l|}{ Mental health problems [30] } \\
\hline Yes & 30 & 37 & $27-48$ & 11 & 37 & $20-54$ \\
\hline No & 51 & 63 & $53-74$ & 19 & 63 & $46-80$ \\
\hline \multicolumn{7}{|l|}{ Unprotected sex [30] } \\
\hline Yes & 45 & 56 & $45-67$ & 22 & 73 & $57-89$ \\
\hline No & 36 & 44 & $33-55$ & 8 & 27 & $11-42$ \\
\hline \multicolumn{7}{|l|}{ Tested for HIV (ever) } \\
\hline Yes & 34 & 42 & $31-53$ & 11 & 37 & $20-54$ \\
\hline No & 46 & 58 & $47-69$ & 19 & 63 & $46-80$ \\
\hline HIV + (serology) & 3 & 4 & $0-8$ & 0 & $\mathrm{n} / \mathrm{a}$ & $\mathrm{n} / \mathrm{a}$ \\
\hline Hep B + (HBSAg) & 5 & 6 & $1-11$ & 0 & $\mathrm{n} / \mathrm{a}$ & $\mathrm{n} / \mathrm{a}$ \\
\hline Hep C + (HCVAB) & 0 & $\mathrm{n} / \mathrm{a}$ & $n / a$ & 0 & $\mathrm{n} / \mathrm{a}$ & $\mathrm{n} / \mathrm{a}$ \\
\hline \multicolumn{7}{|c|}{ Social services use (e.g., shelter, food bank) [30] [*] } \\
\hline Yes & 27 & 33 & $23-43$ & 4 & 13 & $1-25$ \\
\hline No & 54 & 67 & $57-77$ & 26 & 87 & $75-99$ \\
\hline \multicolumn{7}{|c|}{ General health services use (e.g., community health centre, hospital) [30] [*] } \\
\hline Yes & 8 & 10 & $4-17$ & 9 & 30 & $14-46$ \\
\hline No & 73 & 90 & $84-97$ & 21 & 70 & $54-86$ \\
\hline \multicolumn{7}{|c|}{ Specialized mental health or addiction services use [30] [*] } \\
\hline Yes & 0 & $\mathrm{n} / \mathrm{a}$ & $\mathrm{n} / \mathrm{a}$ & 3 & 10 & $0-21$ \\
\hline No & 69 & 100 & $\mathrm{n} / \mathrm{a}$ & 26 & 90 & $79-101$ \\
\hline
\end{tabular}

findings may support calls for both an expansion of treatment resources at least in the specific contexts of our study, as well as for existent services to be more effectively tailored to the target population; these are supported by recent related analyses finding that crack users predominantly refrain from utilizing existing services yet strongly desire to access suitable treatment if available to them [9]. Substantive service expansions have recently been implemented in Brazil; for example, the number of community-based help centers designated for alcohol and drug problems (CAPS-AD) almost doubled from 1010 (2006) to 1803 (2012) [24]. These efforts, however, appear to be insufficient to date. In addition, fundamental discussions are ongoing regarding the nature and range of treatment options needed for crack use [25]. While several of the differences (e.g., social marginalization, health risks/status) we found between the samples are not easily amenable to correction by interventions, these imply that efforts to connect crack users with treatment in particular should focus on the most marginalized users and those characterized by key health risks or problems; these efforts may best occur by community- and/or peer-based based outreach or other targeted efforts. 
Our study's limitations include that it relied on data from relatively small, non-representative convenience samples, including possible selection biases, e.g. as related to sampling, which therefore cannot be generalized. Data collection utilized self-report methods (except for BBV testing) which cannot be objectively validated and social desirability dynamics may have influenced responses however, study and assessment design (including protection of participant identity and data confidentiality) and experiences from other studies have shown similar data to be valid [26]. Samples were not assessed by clinical diagnosis instruments for severity of drug problems or clinical needs (e.g., crack dependence); however, both samples fulfilled the same eligibility criteria regarding intensive crack use, and were hence comparable on these grounds. Further, our study assessed treatment participation but not treatment outcomes.

In sum, we found important differences between inand out-of-treatment crack users in the specific context of RdJ, Brazil; these suggest a need for improved treatment service availability, access and delivery - with particular attention to the most marginalized and high-risk users - in the target population.

\section{Abbreviations}

BBV: Blood borne virus; HBV: Hepatitis B virus; HCV: Hepatitis C virus; HIV: Human immunodeficiency virus; IDU: Injection drug use; Rdj: Rio de Janeiro; SPSS: Statistical package for the social sciences.

\section{Competing interests}

The authors declare that they have no competing interests.

\section{Authors' contributions}

MC, FB, BF designed the study protocol and data analysis plan. NB managed the study data and conducted the data analysis. CB and JG conducted relevant literature searches and reviews, and integrated them with study data. BF, MC and FB jointly led the manuscript writing. All authors contributed to data interpretation and manuscript revisions, and have read and approved the final manuscript.

\section{Acknowledgments}

The authors acknowledge research funding from the Brazilian federal Ministry of Health as well as research exchange funds from the Association of Universities and Colleges of Canada, for the present study. BF acknowledges salary support from a CIHR/PHAC Chair in Applied Public Health. Neither funder had any role in the study design, collection, analysis or interpretation of the data; in the writing the manuscript; or in the decision to submit the manuscript for publication.

\section{Author details}

${ }^{1}$ Institute of Psychiatry, Federal University of Rio de Janeiro, Av. Venceslau Bras, 71 Fundos, Rio de Janeiro 22290-140, Brazil. ${ }^{2}$ Institute of Communication and Scientific Information \& Technology for Health, Oswaldo Cruz Foundation, Av. Brazil, 4365 - Manguinhos, Rio de Janeiro 21040-360, Brazil. ${ }^{3}$ Centre for Applied Research in Mental Health and Addiction (CARMHA), Faculty of Health Sciences, Simon Fraser University, 2400-515 West Hastings St., Vancouver V6B 5 K3, Canada. ${ }^{4}$ Social \& Epidemiological Research, Centre for Addiction and Mental Health, 33 Russell St., Toronto M6J $1 \mathrm{H} 4$, Canada. ${ }^{5}$ Department of Psychiatry, University of Toronto, 250 College Street, Toronto M5T 1R8, Canada.

Received: 4 October 2013 Accepted: 18 December 2013

Published: 10 January 2014

\section{References}

1. Dualibi LB, Ribeiro M, Laranjeira R: Profile of cocaine and crack users in Brazil. Cad Saude Publica 2008, 24(Suppl 4):S545-s557.

2. Galduróz JCF, Noto AR, Nappo SA, Carlini EA: Household survey on drug abuse in Brazil: study involving the 107 major cities of the country2001. Addict Behav 2005, 30(3):545-556.

3. Chaves TV, Sanchez ZM, Ribeiro LA, Nappo SA: Crack cocaine craving: behaviors and coping strategies among current and former users. Rev Saude Publica 2011, 45(6):1168-1175.

4. Nunes CLX, Andrade T, Galvão-Castro B, Bastos Fl, Reingold A: Assessing risk behaviors and prevalence of sexually transmitted and blood-borne infections among female crack cocaine users in Salvador-Bahia, Brazil. Braz J Infect Dis 2007, 11(6):561-566.

5. Malta M, Monteiro S, Lima RM, Bauken S, de Marco A, Zuim GC, Bastos Fl, Singer M, Strathdee SA: HIV/AIDS risk among female sex workers who use crack in Brazil. Rev Saude Publica 2008, 42(5):830-837.

6. Bastos Fl: Structural violence in the context of drug policy and initiatives aiming to reduce drug-related harm in contemporary Brazil: a review. Subst Use Misuse 2012, 47(13-14):1603-1610.

7. Dias AC, Ribeiro M, Dunn J, Sesso R, Laranjeira R: Follow-up study of crack cocaine users: situation of the patients after 2,5 , and 12 years. Subst Abus 2008, 29(3):71-79

8. Malta M, Cavalcanti S, Gliksman L, Adlaf E, Hacker A, Bertoni N, Massard E, Bastos Fl: Behavior and major barriers faced by non-injectable drug users with HBV/HCV seeking treatment for hepatitis and drug addiction in Rio de Janeiro, Brazil. Cien Saude Colet 2011, 16(12):4777-4786

9. Cruz MS, Andrade T, Bastos FI, Leal E, Bertoni N, Melo-Villar L, Tiesmaki M, Fischer B: Key drug use, health and socio-economic characteristics of young crack users in two Brazilian cities. Int J Drug Policy 2013 24(5):432-438

10. Pottieger AE, Tressell PA, Surratt HL, Inciardi JA, Chitwood DD: Drug use patterns of adult crack users in street versus residential treatment samples. J Psychoactive Drugs 1995, 27(1):27-38.

11. Ross J, Teesson M, Darke S, Lynskey M, Ali R, Ritter A, Cooke R: The characteristics of heroin users entering treatment: findings from the Australian treatment outcome study (ATOS). Drug Alcohol Rev 2005, 24(5):411-418

12. van der Poel A, Barendregt C, van de Mheen D: Drug users' participation in addiction care: different groups do different things. J Psychoactive Drugs 2006, 38(2):123-132.

13. Schwartz RP, Kelly SM, O'Grady KE, Mitchell SG, Brown BS: Antecedents and correlates of methadone treatment entry: a comparison of out-oftreatment and in-treatment cohorts. Drug Alcohol Depend 2011, 115(1):23-29.

14. Ferri CP, Gossop M, Laranjeira RR: High dose cocaine use in São Paulo: a comparison of treatment and community samples. Subst Use Misuse 2001, 36(3):237-255

15. Marmot MG, Wilkinson RG: Social determinants of health. Oxford, UK: Oxford University Press; 1999.

16. Galea S, Vlahov D: Social determinants and the health of drug users: socioeconomic status, homelessness, and incarceration. Public Health Rep 2002, 117(Suppl 1):S135-S145.

17. Scheinmann R, Hagan H, Lelutiu-Weinberger C, Stern R, Des Jarlais DC, Flom $P L$, Strauss S: Non-injection drug use and Hepatitis $C$ virus: a systematic review. Drug Alcohol Depend 2007, 89(1):1-12.

18. Rhodes T, Singer M, Bourgois P, Friedman S, Strathdee $S$ : The social structural production of HIV risk among injecting drug users. Soc Sci Med 2005, 61(5):1026-1044.

19. McMahon TJ, Winkel JD, Suchman NE, Luthar SS: Drug dependence, parenting responsibilities, and treatment history: why doesn't mom go for help? Drug Alcohol Depend 2002, 65(2):105-114.

20. Saum CA, Hiller ML, Leigey ME, Inciardi JA, Surratt HL: Predictors of substance abuse treatment entry for crime-involved, cocaine-dependent women. Drug Alcohol Depend 2007, 91(2-3):253-259.

21. Haller DL, Miles DR, Dawson KS: Factors influencing treatment enrollment by pregnant substance abusers. Am J Drug Alcohol Abuse 2003, 29(1):117-131.

22. Metsch LR, McCoy HV, McCoy CB, Miles CC, Edlin BR, Pereyra M: Use of health care services by women who Use crack cocaine. Women Health 1999, 30(1):35-51. 
23. Siegal HS, Falck RS, Carlson RG, Wang J, Rahman AM: Health service research among crack-cocaine users: a case study from the Midwest. Am Behav Sci 1998, 41(8):1063-1078.

24. Ministério da Saúde da Brasil: Saúde Mental em Dados 11 (ano VII, no 11). Brasilia: Ministério da Saúde; 2012.

25. Bastos Fl: Against the tide: current perspectives in Brazilian drug policy. Cad Saude Publica 2013, 29(2):216-218.

26. Darke S: Self-report among injecting drug users: a review. Drug Alcohol Depend 1998, 51(1):253-263.

doi:10.1186/1747-597X-9-2

Cite this article as: Cruz et al:: Comparing key characteristics of young adult crack users in and out-of-treatment in Rio de Janeiro, Brazil. Substance Abuse Treatment, Prevention, and Policy 2014 9:2.

\section{Submit your next manuscript to BioMed Central and take full advantage of:}

- Convenient online submission

- Thorough peer review

- No space constraints or color figure charges

- Immediate publication on acceptance

- Inclusion in PubMed, CAS, Scopus and Google Scholar

- Research which is freely available for redistribution 